\title{
Event-related induced frontal alpha as a marker of lateral prefrontal cortex activation during cognitive reappraisal
}

\author{
Muhammad A. Parvaz • Annmarie MacNamara • \\ Rita Z. Goldstein • Greg Hajcak
}

Published online: 7 July 2012

(C) Psychonomic Society, Inc. 2012

\begin{abstract}
Electrocortical activity, typically used to track the effects of cognitive reappraisal on the processing of emotional stimuli, has not been used to index the prefrontalcortex-mediated regulatory mechanisms responsible for these effects. In the present study, we examined the novel possibility that induced frontal alpha (i.e., $8-13 \mathrm{~Hz}$ ), shown to reflect the inhibition and disengagement of task-relevant cortical regions, may be quantified to explore cortical activation that is specifically enhanced during cognitive reappraisal. For this purpose, 44 participants viewed unpleasant and neutral pictures followed by auditory instructions to either continue viewing the picture or reduce their emotional response to the picture by making the picture seem less emotional (i.e., cognitive reappraisal). In line with previous work, unpleasant pictures elicited a larger late positive potential (LPP) than did neutral pictures. Also corroborating previous work, the mid-latency LPP was reduced when pictures were cognitively reappraised. However, the present study showed for the first time that whereas unpleasant pictures elicited higher frontal alpha power bilaterally than did the neutral pictures, frontal alpha power was reduced (indicative of more activation and cognitive control) during cognitive reappraisal of both picture types over the left hemisphere. Taken together, the LPP and event-related induced frontal-alpha findings contribute unique information about the distinct neural substrates and cognitive processes underlying reappraisal.
\end{abstract}

M. A. Parvaz $(\bowtie) \cdot$ R. Z. Goldstein

Medical Research, Brookhaven National Laboratory,

30 Bell Avenue, Bldg. 490,

Upton, NY 11973-5000, USA

e-mail: mparvaz@bnl.gov

A. MacNamara $\cdot$ G. Hajcak

Psychology, Stony Brook University,

Stony Brook, NY 11794, USA
Keywords Emotion · Regulation · Cognitive control · Amygdala $\cdot$ Prefrontal cortex $\cdot$ ERPs

Emotion regulation refers to the processes engaged when individuals try to influence the type or amount of emotion that they experience and how emotions are expressed (Gross, 1998b). Emotion regulatory behaviors and strategies are normally used to increase or decrease emotional experiences, and successful emotion regulation is related to beneficial psychological, social, and physical health outcomes (Gross, 2002).

One of the most flexible and efficacious emotion regulation strategies is reappraisal, which involves reinterpreting the meaning of emotionally evocative stimuli (Gross, 1998b; Gross \& Levenson, 1993; Richards \& Gross, 2000). By changing a stimulus's affective value, reappraisal can effectively up- or down-regulate subjective reports of emotion, facial expression, and physiological measures of arousal (Dillon \& Labar, 2005; Eippert et al., 2007; Gross, 1998a; Gross \& Levenson, 1997; Hajcak, Moser, \& Simons, 2006; Hajcak \& Nieuwenhuis, 2006; Jackson, Malmstadt, Larson, \& Davidson, 2000). A working model of the cognitive control of emotion (Ochsner, Bunge, Gross, \& Gabrieli, 2002) posits that emotion generation and regulation involve the interaction of appraisal systems, such as the amygdala (e.g., encoding the affective properties of the stimuli in a bottom-up fashion) with control systems implemented in the prefrontal cortex (PFC, which supports topdown cognitive control; Miller, 2000; Ochsner et al., 2002; Ochsner \& Gross, 2005; Ochsner, Ray, et al., 2004).

Functional magnetic resonance imaging (fMRI) studies of reappraisal have provided evidence for this model. These studies implicate increases in ventromedial and lateral PFC activity (Johnstone, van Reekum, Urry, Kalin, \& Davidson, 2007; Ochsner et al., 2002; Ochsner, Ray, et al., 2004; Wager, Davidson, Hughes, Lindquist, \& Ochsner, 2008) and decreases in amygdala activity (Ochsner \& Gross, 
2007; Phillips, Henry, Hosie, \& Milne, 2008) when negative emotion is down-regulated via reappraisal. Specifically, left lateral PFC has been shown to be differentially activated during the cognitive reappraisal of unpleasant stimuli (Davidson, 2004; Goldin, McRae, Ramel, \& Gross, 2008; however, see Ochsner \& Gross, 2007; Ochsner, Ray, et al., 2004; Wager et al., 2008).

In addition to fMRI, event-related potentials (ERPs) have also been used to provide more temporally fine-grained indices of the effects of reappraisal. Specifically, the late positive potential (LPP), a widely distributed ERP component that is larger throughout the presentation of emotional as compared to neutral pictures and words (Cuthbert, Schupp, Bradley, Birbaumer, \& Lang, 2000; Dillon, Cooper, Grent-'t-Jong, Woldorff, \& LaBar, 2006; Foti \& Hajcak, 2008; Hajcak, Dunning, \& Foti, 2007; Hajcak \& Olvet, 2008; Pastor et al., 2008; Schupp et al., 2000) has been shown to be sensitive to reappraisal instructions (Hajcak \& Nieuwenhuis, 2006; Krompinger, Moser, \& Simons, 2008; Moser, Krompinger, Dietz, \& Simons, 2009). For example, Hajcak and Nieuwenhuis found that when participants were asked to reappraise unpleasant pictures, the LPP was reduced relative to the control condition. Similar modulations of the LPP following more open-ended emotion regulation instructions have also been reported (Krompinger et al., 2008; Moser, Hajcak, Bukay, \& Simons, 2006). This LPP modulation is thought to share similar functional sensitivity with amygdala reactivity in response to emotion regulation manipulations (Hajcak, MacNamara, \& Olvet, 2010).

Although ERPs have been used to track the effects of cognitive reappraisal on the processing of emotional stimuli (i.e., as a dependent variable), electrocortical activity has not been used to index the PFC-mediated regulatory mechanisms responsible for these effects. In the present study, we examined the novel possibility that event-related EEG oscillations may be quantified to explore cortical activation that is enhanced during cognitive reappraisal. Specifically, frontal alpha (i.e., $8-13 \mathrm{~Hz}$ ) appears to reflect the inhibition and disengagement of task-relevant cortical regions (Klimesch, 1999; Klimesch, Doppelmayr, Rohm, Pollhuber, \& Stadler, 2000; Klimesch, Sauseng, \& Hanslmayr, 2007; Knyazev, 2007). For example, task-related decreases in alpha power have been reported in response to increased attention (Babiloni, Miniussi, et al., 2004; Dockree et al., 2004; Pfurtscheller \& Lopes da Silva, 1999), memory retrieval (Babiloni, Babiloni, et al., 2004; Hwang et al., 2005; Klimesch, 1999; Krause, Astrom, Karrasch, Laine, \& Sillanmaki, 1999), and other cognitive processes related to frontal regulatory mechanisms. Thus, reduced power in the alpha band appears to index increased frontal activation.

In line with previous work, we predicted that the parietal LPP would be larger for unpleasant than for neutral pictures and that the LPP would be reduced following instructions to reappraise unpleasant pictures. On the basis of fMRI research implicating increased activity in left frontal regions during reappraisal, we examined whether cognitive reappraisal would be accompanied by reduced alpha spectral power over left frontal regions and whether greater decreases in frontal alpha (i.e., increased frontal activation) would predict a reduced LPP. Additionally, although the EEG/ERP evidence regarding gender differences in emotion processing and regulation is not very clear (Bradley, Codispoti, Sabatinelli, \& Lang, 2001; Meyers \& Smith, 1987; Rozenkrants \& Polich, 2008; Weinberg \& Hajcak, 2010), we explored gender differences in the proposed LPP and alpha modulation during cognitive reappraisal of emotional stimuli.

\section{Method}

\section{Participants}

A group of 49 undergraduate students (23 male, 26 female) participated in the study. Five of the participants were excluded due to poor quality EEG recordings; therefore, 44 participants ( 23 male, 21 female) were included in the final EEG analyses. The study was approved by the Stony Brook University Institutional Review Board (IRB), and all participants gave informed consent and received course credit.

Stimulus materials

A set of 50 unpleasant pictures (e.g., car crashes or angry dogs) and 50 neutral pictures (e.g., neutral landscapes or household objects) were selected from the International Affective Picture System ${ }^{1}$ (IAPS; Lang, Bradley \& Cuthbert, 2005). Normative ratings indicated that the unpleasant pictures were less pleasant (valence: $M=2.51$, $S D=0.78)$ and more emotionally arousing $(M=5.78, S D=$ $0.68)$ than the neutral pictures $(M=5.02, S D=0.44$, and $M$ $=3.44, S D=0.41$, respectively; higher numbers indicate more pleasant and higher arousal ratings). Each picture was displayed in color and filled the computer screen (which measured $48.26 \mathrm{~cm}$ diagonally). Participants were seated approximately $60 \mathrm{~cm}$ from the screen, and the images

\footnotetext{
${ }^{1}$ The unpleasant IAPS pictures were 1201, 1302, 1525, 1930, 2053, 2095, 2120, 2130, 2141, 2205, 2352.2, 2455, 2661, 2683, 2688, 2691, $2700,2703,2710,2716,2717,2750,2810,2811,3005.1,3015,3016$, $3017,3030,3053,3063,3168,3181,3220,3225,3266,3301,3530$, $6020,6190,6212,6315,6415,6570.1,6831,9252,9420,9430,9570$, and 9635.1; the neutral IAPS pictures were 2102, 2191, 2200, 2215, $2272,2280,2305,2383,2385,2393,2441,2446,2512,2514,2516$, $2518,2575,2579,2580,2593,2595,2745.1,2980,5510,5530,5531$, 5535, 7030, 7036, 7037, 7038, 7039, 7043, 7050, 7054, 7056, 7180, 7211, 7234, 7236, 7493, 7500, 7546, 7547, 7590, 7700, 7705, 7710, 7920 , and 9913.
} 
occupied about $40^{\circ}$ of visual angle horizontally and vertically. Partway through picture presentation, the participants heard the word "normal" or "reduce" played through earphones, which served as the emotion regulation instructions.

\section{Procedure}

The participants were told that they would be viewing unpleasant and neutral pictures and that during picture presentation they would hear one of two words. If they heard the word "normal," participants were told that they should continue viewing the picture as they normally would. If they heard the word "reduce," they were told that they should reduce their emotional response to the picture by making the picture seem less emotional. The participants were told that they should do this by changing either the meaning of the picture or their perspective on the depicted characters and events. For example, they could tell themselves that the people depicted in a house fire would survive, or that the photo of a gruesome war scene was taken from a movie. The experimenter provided examples by presenting IAPS pictures and reinterpreting the picture meanings for the participant. Special attention was paid to the neutral pictures; specifically, the experimenter explained that it might be difficult for participants to reduce their response to a picture that was already relatively neutral, but that they should try to do so nonetheless. Again, the experimenter gave examples using neutral IAPS pictures (e.g., a building in a picture was boring and nothing interesting happened there).

Next, participants performed six practice trials (on IAPS pictures that were not used in the actual task) to familiarize themselves with the paradigm. After each of the "reduce" trials, the experimenter asked participants to indicate how they had reduced their emotional response to the picture, thus providing an opportunity for the experimenter to determine that participants had understood the directions and were completing the task as instructed (i.e., by using cognitive reappraisal).

Similarly to other emotion regulation paradigms (e.g., Moser et al., 2006), and to minimize the task difficulty, trials were blocked by picture type into four blocks - two neutral and two unpleasant. The block order was determined randomly for each participant. Prior to each picture-type block, participants were informed about the types of pictures that they would be seeing in the upcoming block (e.g., the screen read, "In the next block, you will only see unpleasant pictures.").

Each trial began with a white fixation cross that was presented in the center of a black background for $1,000 \mathrm{~ms}$. Following this, participants viewed an unpleasant or neutral picture, depending on the block; $1,000 \mathrm{~ms}$ after picture onset, they received the auditory instruction informing them to continue viewing the picture as they normally would ("normal") or to reduce their emotional response to the picture using cognitive reappraisal ("reduce"). The picture remained onscreen for $6,000 \mathrm{~ms}$ beyond the instruction; thus, the total picture presentation time was $7,000 \mathrm{~ms}^{2}$ Participants were asked to reduce their emotional response to exactly half of the unpleasant and half of the neutral pictures in the experiment. Across the entire experiment, there were 100 trials: 25 unpleasant normal, 25 unpleasant reduce, 25 neutral normal, and 25 neutral reduce. Each participant viewed all pictures, and picture assignments to the "reduce" or "normal" conditions were determined randomly within the constraints noted above. The order of the "reduce" and "normal" trials was determined randomly for each participant; the intertrial interval was $1,000 \mathrm{~ms}$, during which time participants viewed a white fixation cross centered on a black background. The participants received a break after each block.

\section{EEG recording and data reduction}

Continuous EEG was recorded using an elastic cap and the ActiveTwo BioSemi system (BioSemi, Amsterdam, The Netherlands). Sixty-four electrode sites were used, based on the 10-20 system, as well as one electrode on each of the left and right mastoids. Four facial electrodes recorded the electrooculogram (EOG) generated from eyeblinks and eye movements: Vertical eye movements and blinks were measured with two electrodes placed $\sim 1 \mathrm{~cm}$ above and below the right eye; horizontal eye movements were measured with two electrodes placed $\sim 1 \mathrm{~cm}$ beyond the outer edge of each eye. The EEG signal was preamplified at the electrode to improve the signal-to-noise ratio. The data were digitized at 24-bit resolution with a least significant bit (LSB) value of $31.25 \mathrm{nV}$ and a sampling rate of $512 \mathrm{~Hz}$, using a low-pass fifth-order sync filter with a $-3-\mathrm{dB}$ cutoff point at $104 \mathrm{~Hz}$. Each active electrode was measured online with respect to a common mode sense active electrode producing a monopolar (nondifferential) channel.

Offline preprocessing was performed using SPM8 (Wellcome Department of Cognitive Neurology, London, UK; www.fil.ion.ucl.ac.uk/spm) and custom MATLAB (The MathWorks Inc., Natick, MA) scripts. Data were filtered with low and high cutoffs of 0.01 and $30 \mathrm{~Hz}$, respectively, and were then re-referenced to the averaged electrical activity from all 64 scalp sites. Due to the onsets of two events in each trial (i.e., the picture followed by the auditory instruction), two separate analyses were conducted. First, ERPs were analyzed in response to picture onset; to this end, the EEG was segmented for unpleasant and neutral pictures

\footnotetext{
${ }^{2}$ On approximately one-third of the trials in each condition (randomly selected), participants received a startle probe immediately following picture offset; these data are not reported here.
} 
beginning $200 \mathrm{~ms}$ prior to the picture onset and continuing for $1,000 \mathrm{~ms}$ (i.e., until the onset of the reappraisal instruction). Second, for the analysis of the electrophysiological response to reappraisal, the EEG was segmented for each condition beginning $200 \mathrm{~ms}$ prior to the instruction onset and continuing for $6,000 \mathrm{~ms}$ (i.e., until the end of the picture presentation). For each trial, the baseline was defined as the $200 \mathrm{~ms}$ prior to the event (picture or instruction onset), which was subtracted from the poststimulus onset data for baseline correction.

Eye-blink and ocular corrections were performed using the partial signal space projection (pSSP) method proposed by Nolte and Hämäläinen (2001), such that the contribution to the estimated spatial structure of eye-blink artifact was removed only from the artifact-ridden epochs, leaving as much information as possible in the data (Nolte \& Hämäläinen, 2001). This artifact rejection procedure identified a voltage step of more than $75 \mu \mathrm{V}$ between sample points and a peak-to-peak voltage difference of $150 \mu \mathrm{V}$ within an epoch. Additional artifacts were identified through visual inspection, and the contaminated epochs were subsequently rejected.

Robust averaging was used to create artifact-free ERPs (Wager, Keller, Lacey, \& Jonides, 2005); spectral power over the alpha $(8-13 \mathrm{~Hz})$ frequency range was obtained by applying a Morlet wavelet transform from $150 \mathrm{~ms}$ before the onset of the auditory instruction to 5,500 $\mathrm{ms}$ after the auditory instruction. This "windowing" of the original epoch was performed to avoid edge effects - distortions in the frequency transformation at the edges of an epoch (Harris, 1978). To compute induced (non-phase-locked) spectral power, the average waveform was subtracted from each individual trial before applying the time-frequency transform to the single-trial data, which were then averaged to yield induced oscillatory power. The resulting spectral power over time was expressed as percentage amplitude changes relative to a prestimulus baseline period, to standardize power levels across the frequency band. Spectral power was than computed at each electrode as the average alpha activity over the poststimulus epoch length.

\section{Statistical analyses}

Quantification of electrocortical signals was performed separately for the pre- and postinstruction durations. In line with prior work in which pictures have been presented for durations greater than 1,000 ms (Dunning et al., 2011; Foti \& Hajcak, 2008; Hajcak et al., 2010; Littel \& Franken, 2011), we divided the postinstruction period into several time windows. Note that these windows (1,500-2,000, $2,000-4,500$, and 4,500-7,000 ms) were labeled relative to the picture onset ("early," "mid," and "late"). Since the preinstruction period only lasted $1,000 \mathrm{~ms}$, we did not divide this period into more than one time window, which is also consistent with our prior research (MacNamara, Foti, \& Hajcak, 2009; MacNamara, Ochsner, \& Hajcak, 2011).
Importantly, the LPP was scored in an identical time window in both the pre- and early postinstruction periods (i.e., from 500 to $1,000 \mathrm{~ms}$ following both picture and instruction onsets). The LPP was scored where it was maximal-at a pooling consisting of electrodes $\mathrm{CPz}, \mathrm{Pz}$, and $\mathrm{POz}$ (see Fig. 1A). Given our hypothesis regarding frontal alpha, we quantified alpha-band power separately for each hemisphere (left, at FC5, F7, F3; right, at FC4, F8, and F4).

The preinstruction LPP was analyzed with a 2 (picture type: unpleasant or neutral) $\times 2$ (gender: male or female) mixed-model analysis of variance (ANOVA). The postinstruction LPP was analyzed with a 3 (LPP window: early, middle, or late) $\times 2$ (picture type: unpleasant or neutral) $\times 2$ (regulation: normal or reduced) $\times 2$ (gender: male or female) mixed-model ANOVA. Alpha power was analyzed using a 2 (laterality: left or right) $\times 2$ (picture type: unpleasant or neutral) $\times 2$ (regulation: normal or reduced) $\times 2$ (gender: male or female) mixed-model ANOVA. In all analyses, the Greenhouse-Geisser correction was applied for cases in which Mauchly's test showed that the assumption of sphericity was not met. Significant interactions were followed up using post-hoc tests. If significant, the LPP and alpha effects were intercorrelated separately for each task condition and also as differential scores (normal minus reduced) for each picture type in order to explore the underlying associations between these electrocortical measures.

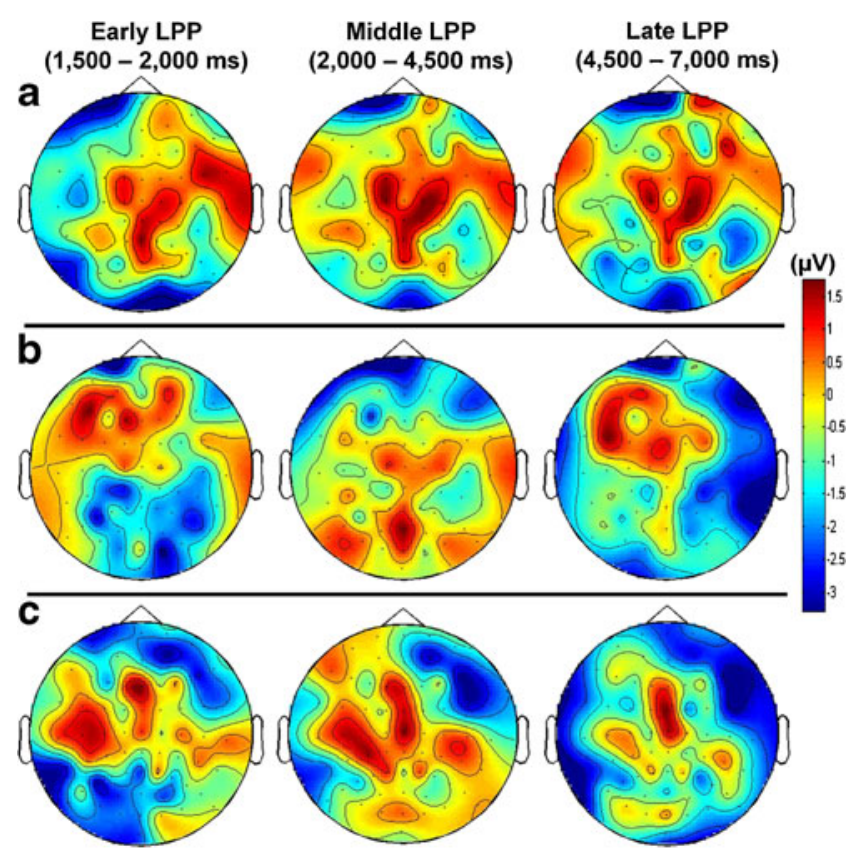

Fig. 1 Differential scalp topographies of late positive potential (LPP) amplitudes (post reappraisal instruction onset) in response to a normally viewed unpleasant pictures minus normally viewed neutral pictures; b normally viewed unpleasant pictures minus those that were reappraised; and $\mathbf{c}$ normally viewed neutral pictures minus those that were reappraised, during the early (left), middle (center), and late (right) LPP windows 


\section{Results}

Figure 2 shows the grand-averaged waveforms from 0 to $7,000 \mathrm{~ms}$ following picture onset for three representative midline electrodes. The LPP amplitudes and alpha power for each task condition are presented in Table 1.
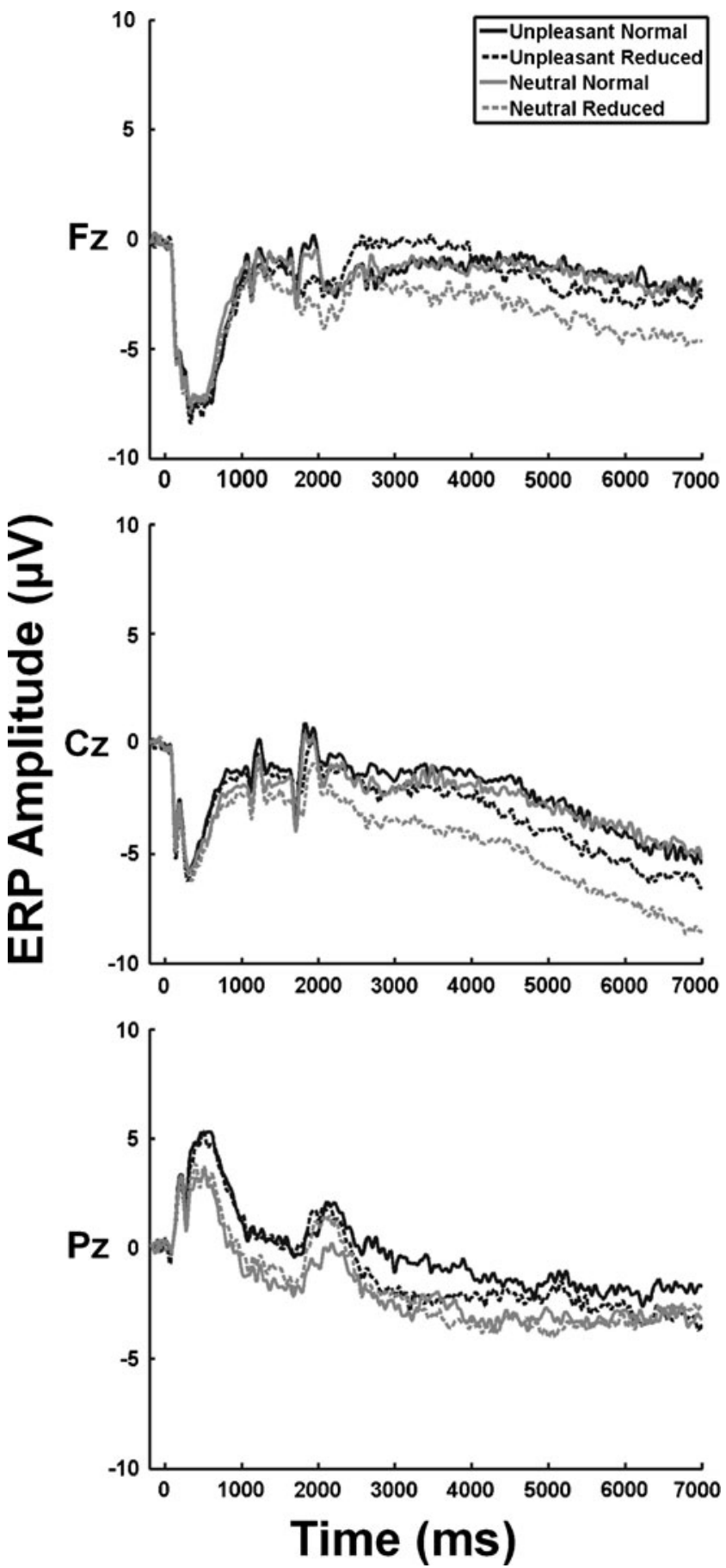

Fig. 2 Grand-averaged ERP waveforms from 0 to 7,000 $\mathrm{ms}$ following picture onset at representative midline electrode sites, presented separately for unpleasant and neutral pictures in each of the "normal" and "reduced" conditions
Since none of the analyses showed significant gender differences and/or gender-related interactions ( $p \mathrm{~s}>.1)$, the data were reanalyzed without modeling Gender as a factor. Thus, the preinstruction LPP was reanalyzed using paired $t$ tests (unpleasant vs. neutral); postinstruction LPP, using a 3 (LPP window: early, middle, or late) $\times 2$ (picture type: unpleasant or neutral) $\times 2$ (regulation: normal or reduced) ANOVA; and postinstruction alpha, using a 2 (laterality: left or right) $\times 2$ (picture type: unpleasant or neutral) $\times 2$ (regulation: normal or reduced) ANOVA. The results of these analyses are reported below.

\section{Pre-instruction ERPs}

As expected, there was a significantly higher LPP amplitude in response to unpleasant as compared to neutral pictures $[t$ $(43)=5.06, p<.001$; unpleasant $>$ neutral $]$.

Post-instruction ERPs

We found significant effects of LPP window $[F(2,86)=$ $16.37, p<.001$; early $>$ middle $>$ late $]$ and picture type $[F(1$, $43)=6.48, p<.05$; unpleasant $>$ neutral], as well as an LPP window by regulation interaction $[F(2,86)=3.72, p<.05]$. The three-way interaction between LPP window, picture type, and regulation did not reach significance $[F(2,86)=$ 2.57, $p<.1]$. Post-hoc tests revealed that, unlike in the early and late $(p s>1$ ) LPP windows, reappraisal reduced the LPP in the middle LPP window $[t(43)=2.20, p<.05]$ across participants. This reappraisal effect was primarily driven by the unpleasant pictures $[t(43)=2.70, p<.01]$ rather than the neutral pictures $(p>.1)$, in line with the trend toward a three-way interaction noted above. Other main effects and interactions did not reach significance $(p s>1)$. The scalp distributions of the LPP modulation in response to unpleasant and neutral pictures are shown in Fig. $1 \mathrm{~B}$ and $\mathrm{C}$, respectively.

\section{Post-instruction alpha}

We found a significant effect of picture type $[F(1,43)=$ 4.79, $p<.05$; unpleasant $>$ neutral] and a three-way laterality by picture type by regulation interaction $[F(1,43)=$ $5.25, p<.05]$. The main effect of regulation condition approached but did not reach significance $[F(1,43)=$ $3.56, p=.066$; normal $>$ reduced]; all other main effects and interactions also failed to reach significance ( $p \mathrm{~s}>.1)$.

Post-hoc analyses were performed separately for each hemisphere using a 2 (picture type: unpleasant or neutral) $\times 2$ (regulation: normal or reduced) repeated measures ANOVA. The results indicated a significant effect of picture type in both hemispheres [left, $F(1,43)=3.97, p<.05$; right, $F(1,43)=4.96, p<.05]$, such that alpha power was 
Table 1 ERP amplitudes and EEG spectral power (reported as means $\pm S E M s$ ) for each task condition following instruction onset

\begin{tabular}{lllll}
\hline & Unpleasant Normal & Unpleasant Reduced & Neutral Normal & Neutral Reduced \\
\hline Early LPP $(\mu \mathrm{V})$ & $-0.07 \pm 0.55$ & $-.08 \pm 0.63$ & $-1.04 \pm 0.65$ & $-0.69 \pm 0.53$ \\
Middle LPP $(\mu \mathrm{V})$ & $-0.16 \pm 0.67$ & $-1.74 \pm 0.72$ & $-1.96 \pm 0.82$ & $-2.21 \pm 0.66$ \\
Late LPP $(\mu \mathrm{V})$ & $-1.72 \pm 0.98$ & $-2.88 \pm 0.94$ & $-3.17 \pm 1.10$ & $-3.16 \pm 0.95$ \\
Left Alpha $(\mathrm{dB})$ & $0.32 \pm 0.14$ & $-0.23 \pm 0.16$ & $-0.22 \pm 0.20$ & $-0.39 \pm 0.17$ \\
Right Alpha $(\mathrm{dB})$ & $0.08 \pm 0.14$ & $-0.02 \pm 0.16$ & $-0.14 \pm 0.16$ & $-0.41 \pm 0.19$ \\
\hline
\end{tabular}

significantly higher in response to unpleasant as compared to neutral pictures. However, the regulation effect was only significant in the left hemisphere [left, $F(1,43)=5.05, p<.05$, normal $>$ reduced; right, $p>.1$. The picture type by regulation interaction did not reach significance in either hemisphere $(p s>.1)$. Thus, across all study participants, we found a bilateral increase in frontal alpha power in response to unpleasant as compared to neutral pictures; moreover, alpha power was decreased following reappraisal as compared to control instructions in the left hemisphere (Fig. 3).

In contrast to what we expected, there were no significant correlations between LPP amplitude and frontal alpha power (all $p \mathrm{~s}>.1$ ). Moreover, preinstruction emotional reactivity (LPP amplitude in response to unpleasant pictures minus LPP in response to neutral pictures) did not predict emotion regulation effects (postinstruction LPP amplitude and alpha power in response to pictures that were viewed normally minus those that were reappraised; all $p \mathrm{~s}>.1$ ).

\section{Discussion}

In the present study, we used electrophysiological data to investigate the cortical activation related to cognitive

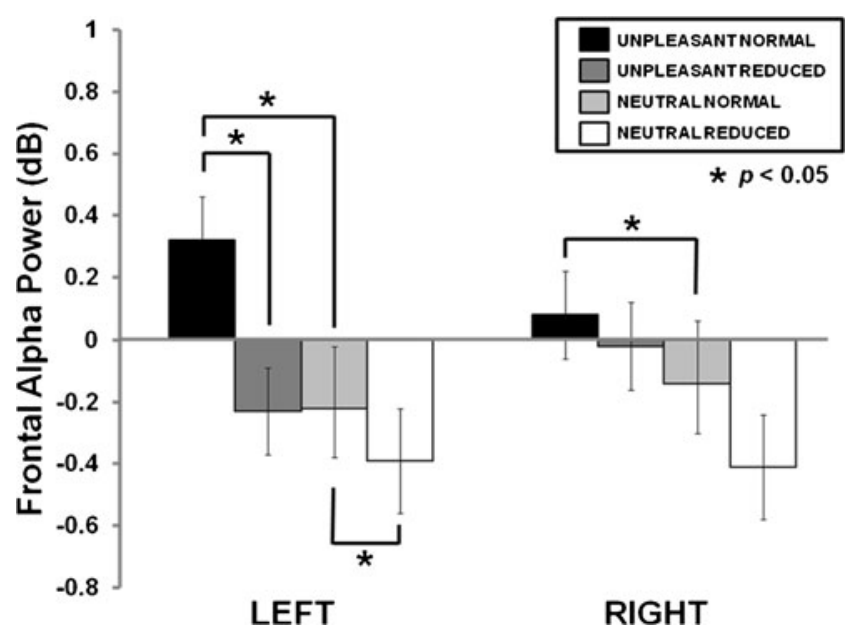

Fig. 3 Induced frontal alpha power for all task conditions (unpleasant normal, unpleasant reduced, neutral normal, and neutral reduced) following the instruction onset, shown separately for each hemisphere reappraisal. In line with previous work, unpleasant pictures elicited a more positive LPP than did neutral pictures (Cuthbert et al., 2000; Foti, Hajcak, \& Dien, 2009; Hajcak et al., 2007; Pastor et al., 2008), and the LPP in response to unpleasant pictures was reduced following instructions to reappraise (Foti \& Hajcak, 2008; Hajcak et al., 2006; Hajcak \& Nieuwenhuis, 2006). In the present study, we also showed that frontal alpha increased bilaterally in response to unpleasant versus neutral pictures. Moreover, cognitive reappraisal was found to reduce left frontal alpha band power, suggesting increased cortical activation in this condition (Klimesch, 1999; Klimesch et al., 2007) and that the left PFC may be differentially activated during cognitive reappraisal (Davidson, 2004; Goldin et al., 2008; Ochsner, Ray, et al., 2004). Finally, the present results did not reveal gender differences in LPP amplitude and frontal alpha power in response to cognitive reappraisal.

The LPP effects (i.e., reduced LPP amplitude in response to reappraised as compared to normally viewed pictures) highlight the role of top-down influences on the evaluation of affective stimuli (Hajcak et al., 2010). In the present study, the effect of reappraisal was observed in the middle LPP window, where reappraisal-related LPP modulations have previously been shown to be maximal (MacNamara et al., 2009). The lack of reappraisal effects in the early window might be attributed to the fact that unlike previous emotion regulation studies (Foti \& Hajcak, 2008; Hajcak et al., 2006; Hajcak \& Nieuwenhuis, 2006), reappraisal instructions were presented after picture onset in the present study, potentially delaying top-down attentional effects (see also Hajcak, Dunning, \& Foti, 2009). During the late LPP window, the effect of reappraisal may not have reached significance because of increased variability in participants' success at sustaining cognitive reappraisal, as is suggested by the high standard errors of the means in this window (Table 1).

The novelty of the present results lies in the finding of reduced left frontal alpha power as a function of cognitive reappraisal. Frontal alpha-band oscillation appears to index cortical inhibition (Klimesch, 1999; Klimesch et al., 2000; Klimesch et al., 2007; Knyazev, 2007), and its reduction has been linked to increased PFC activity during working memory and attentional processes (Klimesch, 1999; Klimesch et al., 2007; Park et al., 2006). In the context of reappraisal, regulatory control and goal-directed monitoring appear to 
rely on the lateral PFC (Botvinick, Braver, Barch, Carter, \& Cohen, 2001; Miller \& Cohen, 2001; Ochsner \& Gross, 2007; Wager et al., 2008). Therefore, reduced frontal alpha power might provide a useful electrocortical index of PFC activation during cognitive reappraisal. Importantly, reappraisal-related reductions in frontal alpha power were observed at left but not at right frontal electrode sites, which is of interest because functional neuroimaging studies have also demonstrated greater activation in left PFC during cognitive reappraisal (Johnstone et al., 2007; Ochsner et al., 2002).

One possible reason for the left-sided bias in alpha modulation could be that reappraisal seems to be a verbally mediated process (Ochsner \& Gross, 2004), and left prefrontal regions have been implicated in interference tasks involving verbal stimuli (Bunge, Ochsner, Desmond, Glover, \& Gabrieli, 2001; D'Esposito, Postle, Jonides, \& Smith, 1999). Specifically, the left inferior frontal gyrus (Broca's area) is implicated in inhibitory control processes (Swick, Ashley, \& Turken, 2008), especially those related to semantic selection (Thompson-Schill et al., 1998) and interference resolution in working memory (Thompson-Schill et al., 2002), and its activity has been shown to be negatively correlated with alpha rhythm (Goldman, Stern, Engel, \& Cohen, 2002). Therefore, future studies might evaluate the possibility of examining frontal alpha in emotion regulation tasks that do not require verbally mediated changes in stimulus meaning (e.g., attentional deployment; Dunning \& Hajcak, 2009; Hajcak et al., 2007; Hajcak, Macnamara, Foti, Ferri, \& Keil, 2011).

Interestingly, our results showed increased alpha in response to unpleasant as compared to neutral pictures across both hemispheres. Similar findings of increased alpha spectral power in response to emotionally salient stimuli have been reported previously (e.g., Aftanas, Varlamov, Pavlov, Makhnev, \& Reva, 2001). Given that conscious down-regulation of emotion may rely on prefrontally mediated inhibition of the amygdala (Beauregard, Lévesque, \& Bourgouin, 2001; Lévesque et al., 2003; Lévesque et al., 2004; Ochsner et al., 2002; Ochsner, Knierim, et al., 2004; Phan et al., 2005; Urry et al., 2006), and given previous reports of a reciprocal relationship between the amygdala and prefrontal brain regions (Amaral \& Price, 1984; Ghashghaei \& Barbas, 2002; Ghashghaei, Hilgetag, \& Barbas, 2007), it is plausible that increased emotional arousal may be associated with reduced frontal activity, manifested in increased frontal alpha for unpleasant relative to neutral pictures. It is important to note, however, that in the present study, LPP amplitude and alpha power were uncorrelated.

The present results showing higher alpha power in response to unpleasant as compared to neutral are also consistent with results from recent neuroimaging studies that have investigated the differences between the effects of spontaneous and effortful emotion regulation. For example, Viviani et al. (2010) showed decreased activity in frontal executive attentional areas (e.g., dorsolateral prefrontal cortex) during spontaneous avoidance of unpleasant relative to neutral stimuli, whereas during intentional emotional regulation, these authors reported increased activity in the dorsolateral PFC. In light of these results, these authors argued that spontaneous emotion regulation should not be attributed to the intense recruitment of effortful control processes (Viviani et al., 2010). Similarly, the present results suggest decreased frontal cortical activation (increased frontal alpha) in response to unpleasant relative to neutral pictures during normal viewing (i.e., spontaneous emotion regulation), as well as increased frontal activation (decreased frontal alpha) during reappraisal (i.e., instructed emotion regulation) as compared to normal-viewing trials.

It should be noted that frontal alpha effects may also arise due to the choice of referencing scheme used in analyzing EEG data (Hagemann, Naumann, \& Thayer, 2001). In keeping with several recently published studies (see, e.g., Accortt, Stewart, Coan, Manber, \& Allen, 2011; Babiloni et al., 2012; Del Percio et al., 2010; Schmidt \& Hanslmayr, 2009), and given some limitations across all reference schemes (Hagemann et al., 2001), we used average referencing to analyze frontal alpha. One limitation of using average referencing is that it produces frontal alpha effects, which are mere reflections of occipital alpha (Hagemann et al., 2001). Nevertheless, the present results of lateralized modulation of frontal alpha in response to cognitive control would not be expected as an artifact of the average reference scheme.

Although there is no precedence for investigating gender differences on LPP amplitude and event-related alpha during emotion regulation per se, recent fMRI studies have reported inconsistent gender differences in the neural correlates of emotion regulation (Domes et al., 2010; McRae, Oschsner, Mauss, Gabrieli, \& Gross, 2008; McRae, Reiman, Fort, Chen, \& Lane, 2008). Specifically, McRae and colleagues (McRae, Ochsner, et al., 2008; McRae, Reiman, et al., 2008) reported enhanced activity in the ventral striatum and parts of the PFC (the rostral anterior cingulate cortex and medial PFC), as well as attenuated amygdala reactivity, in women as compared to men during cognitive reappraisal of emotional stimuli. In contrast, Domes et al. (2010) found greater prefrontal activity in males as compared to females during the down-regulation of negative emotion, with no gender differences in amygdala activity or self-reported regulation success. The lack of gender difference in LPP and frontal alpha modulation in response to cognitive reappraisal, even with as large a sample as the present one, perhaps points to similarities across both genders in recruitment of the underlying neural substrates during reappraisal. 
The present results extend prior neuroimaging findings to ERPs and suggest that the emotion-modulatory effects of reappraisal may stem from interactions between emotional appraisal processes in emotion-related structures, including the amygdala (Ochsner et al., 2002; Ochsner \& Gross, 2004) and in prefrontal regions (D'Esposito, Postle, \& Rypma, 2000; Miller \& Cohen, 2001). Future studies may investigate withinsubjects associations between frontal alpha power and the LPP amplitude by optimizing the study design and data reduction procedures in order to investigate individual variability in emotion regulation. These analyses were not possible in the present study design, due to very low signal-to-noise ratios for each trial. Future studies may also add subjective measures of arousal, ability to regulate emotion, and task difficulty so as to examine emotion regulation as a function of individual differences in the subjective experience of emotional stimuli, and to determine how these measures relate to the frontal and limbic activation measured with fMRI.

Future studies may also investigate neuropsychiatric disorders characterized by deficits in emotion regulation, such as depression, posttraumatic stress disorder, and drug addiction. Drug addiction, for example, involves profound impairments in emotion regulation (Fox, Axelrod, Paliwal, Sleeper, \& Sinha, 2007); however, when asked to volitionally inhibit cue-induced craving in a laboratory environment, some drug-addicted individuals reported lower craving and showed decreased activity in the brain regions (orbitofrontal cortex) that process the motivational values of reinforcers, including drug-related cues, thereby allowing these individuals to retain some level of control over their drug-related cue reactivity (Volkow et al., 2010). These findings can be further explored using LPP and alpha measures to better understand the extent of emotion regulation impairment in drug addiction and related disorders.

In sum, the present study replicates previous findings of reduced LPP amplitudes in response to cognitive reappraisal and provides the first evidence of induced frontal-alpha spectral power reduction as an electrocortical correlate of cognitive reappraisal. These results suggest that time and frequency domain measures of scalp-recorded EEG activity may each contribute uniquely to the study of the neural substrates and cognitive processes underlying reappraisal. These data are largely consistent with existing functional neuroimaging work, which has highlighted the role of the amygdala-prefrontal circuit in emotion regulation, and they suggest that frontal alpha power may be a useful metric of emotion-cognition interactions involving the PFC.

Author note The manuscript was authored by Brookhaven Science Associates, LLC, under Contract No. DE-AC02-98CHI-886 with the U.S. Department of Energy. The United States Government retains, and by accepting the article for publication the publisher acknowledges, a worldwide license to publish or reproduce the published form of this article, or to allow others to do so, for United States Government purposes.

\section{References}

Accortt, E. E., Stewart, J. L., Coan, J. A., Manber, R., \& Allen, J. J. (2011). Prefrontal brain asymmetry and pre-menstrual dysphoric disorder symptomatology. Journal of Affective Disorders, 128, 178-183. doi:10.1016/j.jad.2010.07.017

Aftanas, L., Varlamov, A., Pavlov, S., Makhnev, V., \& Reva, N. (2001). Event-related synchronization and desynchronization during affective processing: Emergence of valence-related timedependent hemispheric asymmetries in theta and upper alpha band. International Journal of Neuroscience, 110, 197-219.

Amaral, D. G., \& Price, J. L. (1984). Amygdalo-cortical projections in the monkey (Macaca fascicularis). The Journal of Comparative Neurology, 230, 465-496. doi:10.1002/cne.902300402

Babiloni, C., Babiloni, F., Carducci, F., Cappa, S. F., Cincotti, F., Del Percio, C., . . Rossini, P. M. (2004). Human cortical responses during one-bit short-term memory: A high-resolution EEG study on delayed choice reaction time tasks. Clinical Neurophysiology, $115,161-170$.

Babiloni, C., Buffo, P., Vecchio, F., Marzano, N., Del Percio, C., Spada, D., . . Perani, D. (2012). Brains "in concert": Frontal oscillatory alpha rhythms and empathy in professional musicians. NeuroImage, 60, 105-116. doi:10.1016/ j.neuroimage.2011.12.008

Babiloni, C., Miniussi, C., Babiloni, F., Carducci, F., Cincotti, F., Del Percio, C., . . . Rossini, P. M. (2004). Sub-second "temporal attention" modulates alpha rhythms: A high-resolution EEG study. Cognitive Brain Research, 19, 259-268. doi:10.1016/ j.cogbrainres.2003.12.010

Beauregard, M., Lévesque, J., \& Bourgouin, P. (2001). Neural correlates of conscious self-regulation of emotion. Journal of Neuroscience, 21, RC165.

Botvinick, M. M., Braver, T. S., Barch, D. M., Carter, C. S., \& Cohen, J. D. (2001). Conflict monitoring and cognitive control. Psychological Review, 108, 624-652. doi:10.1037/0033-295X.108.3.624

Bradley, M. M., Codispoti, M., Sabatinelli, D., \& Lang, P. J. (2001). Emotion and motivation II: Sex differences in picture processing. Emotion, 1, 300-319. doi:10.1037/1528-3542.1.3.300

Bunge, S. A., Ochsner, K. N., Desmond, J. E., Glover, G. H., \& Gabrieli, J. D. E. (2001). Prefrontal regions involved in keeping information in and out of mind. Brain, 124, 2074-2086.

Cuthbert, B. N., Schupp, H. T., Bradley, M. M., Birbaumer, N., \& Lang, P. J. (2000). Brain potentials in affective picture processing: Covariation with autonomic arousal and affective report. Biological Psychology, 52, 95-111. doi:10.1016/S0301-0511 (99)00044-7

Davidson, R. J. (2004). What does the prefrontal cortex "do" in affect: Perspectives on frontal EEG asymmetry research. Biological Psychology, 67, 219-233. doi:10.1016/j.biopsycho.2004.03.008

Del Percio, C., Infarinato, F., Iacoboni, M., Marzano, N., Soricelli, A., Aschieri, P., . . Babiloni, C. (2010). Movement-related desynchronization of alpha rhythms is lower in athletes than non-athletes: A high-resolution EEG study. Clinical Neurophysiology, 121, 482-491. doi:10.1016/j.clinph.2009.12.004

D’Esposito, M., Postle, B. R., Jonides, J., \& Smith, E. E. (1999). The neural substrate and temporal dynamics of interference effects in working memory as revealed by event-related functional MRI. Proceedings of the National Academy of Sciences, 96, 7514 7519.

D’Esposito, M., Postle, B. R., \& Rypma, B. (2000). Prefrontal cortical contributions to working memory: Evidence from event-related fMRI studies. Experimental Brain Research, 133, 3-11.

Dillon, D. G., Cooper, J. J., Grent-'t-Jong, T., Woldorff, M. G., \& LaBar, K. S. (2006). Dissociation of event-related potentials indexing arousal and semantic cohesion during emotional word 
encoding. Brain and Cognition, 62, 43-57. doi:10.1016/ j.bandc. 2006.03 .008

Dillon, D. G., \& Labar, K. S. (2005). Startle modulation during conscious emotion regulation is arousal-dependent. Behavioral Neuroscience, 119, 1118-1124. doi:10.1037/0735-7044.119. 4.1118

Dockree, P. M., Kelly, S. P., Roche, R. A., Hogan, M. J., Reilly, R. B., \& Robertson, I. H. (2004). Behavioural and physiological impairments of sustained attention after traumatic brain injury. Cognitive Brain Research, 20, 403-414. doi:10.1016/ j.cogbrainres.2004.03.019

Domes, G., Schulze, L., Böttger, M., Grossmann, A., Hauenstein, K., Wirtz, P. H., . . . Herpetz, S. C. (2010). The neural correlates of sex differences in emotional reactivity and emotion regulation. Human Brain Mapping, 31, 758-769. doi:10.1002/hbm.20903

Dunning, J. P., \& Hajcak, G. (2009). See no evil: Directing visual attention within unpleasant images modulates the electrocortical response. Psychophysiology, 46, 28-33. doi:10.1111/j.14698986.2008.00723.x

Dunning, J. P., Parvaz, M. A., Hajcak, G., Maloney, T., Alia-Klein, N., Woicik, P. A., . . G Goldstein, R. Z. (2011). Motivated attention to cocaine and emotional cues in abstinent and current cocaine users - An ERP study. European Journal of Neuroscience, 33, 17161723. doi:10.1111/j.1460-9568.2011.07663.x

Eippert, F., Veit, R., Weiskopf, N., Erb, M., Birbaumer, N., \& Anders, S. (2007). Regulation of emotional responses elicited by threatrelated stimuli. Human Brain Mapping, 28, 409-423. doi:10. 1002/hbm.20291

Foti, D., \& Hajcak, G. (2008). Deconstructing reappraisal: Descriptions preceding arousing pictures modulate the subsequent neural response. Journal of Cognitive Neuroscience, 20, 977-988. doi:10.1162/jocn.2008.20066

Foti, D., Hajcak, G., \& Dien, J. (2009). Differentiating neural responses to emotional pictures: Evidence from temporal-spatial PCA. Psychophysiology, 46, 521-530. doi:10.1111/j.1469-8986. 2009.00796.x

Fox, H. C., Axelrod, S. R., Paliwal, P., Sleeper, J., \& Sinha, R. (2007). Difficulties in emotion regulation and impulse control during cocaine abstinence. Drug and Alcohol Dependence, 89, 298301. doi:10.1016/j.drugalcdep.2006.12.026

Ghashghaei, H. T., \& Barbas, H. (2002). Pathways for emotion: Interactions of prefrontal and anterior temporal pathways in the amygdala of the rhesus monkey. Neuroscience, 115, 1261-1279.

Ghashghaei, H. T., Hilgetag, C. C., \& Barbas, H. (2007). Sequence of information processing for emotions based on the anatomic dialogue between prefrontal cortex and amygdala. NeuroImage, 34 , 905-923. doi:10.1016/j.neuroimage.2006.09.046

Goldin, P. R., McRae, K., Ramel, W., \& Gross, J. J. (2008). The neural bases of emotion regulation: Reappraisal and suppression of negative emotion. Biological Psychiatry, 63, 577-586. doi:10.1016/ j.biopsych.2007.05.031

Goldman, R. I., Stern, J. M., Engel, J., Jr., \& Cohen, M. S. (2002). Simultaneous EEG and fMRI of the alpha rhythm. NeuroReport, 13, 2487-2492. doi:10.1097/01.wnr.0000047685.08940.d0

Gross, J. J. (1998a). Antecedent- and response-focused emotion regulation: Divergent consequences for experience, expression, and physiology. Journal of Personality and Social Psychology, 74, 224-237.

Gross, J. J. (1998b). The emerging field of emotion regulation: An integrative review. Review of General Psychology, 2, 271-299.

Gross, J. J. (2002). Emotion regulation: Affective, cognitive, and social consequences. Psychophysiology, 39, 281-291. doi:10. 1017.S0048577201393198

Gross, J. J., \& Levenson, R. W. (1993). Emotional suppression: Physiology, self-report, and expressive behavior. Journal of Personality and Social Psychology, 64, 970-986.
Gross, J. J., \& Levenson, R. W. (1997). Hiding feelings: The acute effects of inhibiting negative and positive emotion. Journal of Abnormal Psychology, 106, 95-103. doi:10.1037/0021843X.106.1.95

Hagemann, D., Naumann, E., \& Thayer, J. F. (2001). The quest for the EEG reference revisited: A glance from brain asymmetry research. Psychophysiology, 38, 847-857.

Hajcak, G., Dunning, J. P., \& Foti, D. (2007). Neural response to emotional pictures is unaffected by concurrent task difficulty: An event-related potential study. Behavioral Neuroscience, 121, 1156-1162. doi:10.1037/0735-7044.121.6.1156

Hajcak, G., Dunning, J. P., \& Foti, D. (2009). Motivated and controlled attention to emotion: Time-course of the late positive potential. Clinical Neurophysiology, 120, 505-510. doi:10.1016/ j.clinph.2008.11.028

Hajcak, G., Macnamara, A., Foti, D., Ferri, J., \& Keil, A. (2011). The dynamic allocation of attention to emotion: Simultaneous and independent evidence from the late positive potential and steady state visual evoked potentials. Biological Psychology. doi:10.1016/j.biopsycho.2011.11.012

Hajcak, G., MacNamara, A., \& Olvet, D. M. (2010). Event-related potentials, emotion, and emotion regulation: An integrative review. Developmental Neuropsychology, 35, 129-155. doi:10.1080/ 87565640903526504

Hajcak, G., Moser, J. S., \& Simons, R. F. (2006). Attending to affect: Appraisal strategies modulate the electrocortical response to arousing pictures. Emotion, 6, 517-522. doi:10.1037/15283542.6.3.517

Hajcak, G., \& Nieuwenhuis, S. (2006). Reappraisal modulates the electrocortical response to unpleasant pictures. Cognitive, Affective, \& Behavioral Neuroscience, 6, 291-297. doi:10.3758/ CABN.6.4.291

Hajcak, G., \& Olvet, D. M. (2008). The persistence of attention to emotion: Brain potentials during and after picture presentation. Emotion, 8, 250-255. doi:10.1037/1528-3542.8.2.250

Harris, F. J. (1978). Use of windows for harmonic-analysis with discrete Fourier-transform. Proceedings of the IEEE, 66, 51-83.

Hwang, G., Jacobs, J., Geller, A., Danker, J., Sekuler, R., \& Kahana, M. J. (2005). EEG correlates of verbal and nonverbal working memory. Behavioral and Brain Functions, 1, 20. doi:10.1186/ 1744-9081-1-20

Jackson, D. C., Malmstadt, J. R., Larson, C. L., \& Davidson, R. J. (2000). Suppression and enhancement of emotional responses to unpleasant pictures. Psychophysiology, 37, 515-522.

Johnstone, T., van Reekum, C. M., Urry, H. L., Kalin, N. H., \& Davidson, R. J. (2007). Failure to regulate: Counterproductive recruitment of top-down prefrontal-subcortical circuitry in major depression. Journal of Neuroscience, 27, 8877-8884. doi:10.1523/ JNEUROSCI.2063-07.2007

Klimesch, W. (1999). EEG alpha and theta oscillations reflect cognitive and memory performance: A review and analysis. Brain Research Reviews, 29, 169-195.

Klimesch, W., Doppelmayr, M., Rohm, D., Pollhuber, D., \& Stadler, W. (2000). Simultaneous desynchronization and synchronization of different alpha responses in the human electroencephalograph: A neglected paradox? Neuroscience Letters, 284, 97-100.

Klimesch, W., Sauseng, P., \& Hanslmayr, S. (2007). EEG alpha oscillations: The inhibition-timing hypothesis. Brain Research Reviews, 53, 63-88. doi:10.1016/j.brainresrev.2006.06.003

Knyazev, G. G. (2007). Motivation, emotion, and their inhibitory control mirrored in brain oscillations. Neuroscience and Biobehavioral Reviews, 31, 377-395. doi:10.1016/j.neubiorev.2006.10.004

Krause, C. M., Astrom, T., Karrasch, M., Laine, M., \& Sillanmaki, L. (1999). Cortical activation related to auditory semantic matching of concrete versus abstract words. Clinical Neurophysiology, 110, 1371-1377. 
Krompinger, J. W., Moser, J. S., \& Simons, R. F. (2008). Modulations of the electrophysiological response to pleasant stimuli by cognitive reappraisal. Emotion, 8, 132-137. doi:10.1037/15283542.8.1.132

Lang, P. J., Bradley, M. M., \& Cuthbert, B. N. (2005). International affective picture system (IAPS): Affective ratings of pictures and instruction manual (Technical Report No. A-6). Gainesville, FL: University of Florida, Center for Research in Psychophysiology.

Lévesque, J., Eugène, F., Joanette, Y., Paquette, V., Mensour, B., Beaudoin, G., . . . Beauregard, M. (2003). Neural circuitry underlying voluntary suppression of sadness. Biological Psychiatry, 53, 502-510.

Lévesque, J., Joanette, Y., Mensour, B., Beaudoin, G., Leroux, J. M., Bourgouin, P., . . . Beauregard, M. (2004). Neural basis of emotional self-regulation in childhood. Neuroscience, 129, 361-369. doi:10.1016/j.neuroscience.2004.07.032

Littel, M., \& Franken, I. H. (2011). Intentional modulation of the late positive potential in response to smoking cues by cognitive strategies in smokers. PLoS One, 6, e27519. doi:10.1371/journal. pone.0027519

MacNamara, A., Foti, D., \& Hajcak, G. (2009). Tell me about it: Neural activity elicited by emotional pictures and preceding descriptions. Emotion, 9, 531-543. doi:10.1037/a0016251

MacNamara, A., Ochsner, K. N., \& Hajcak, G. (2011). Previously reappraised: The lasting effect of description type on pictureelicited electrocortical activity. Social, Cognitive, and Affective Neuroscience. doi:10.1093/scan/nsq053

McRae, K., Ochsner, K. N., Mauss, I. B., Gabrieli, J. D. E., \& Gross, J. J. (2008a). Gender disfferences in emotion regulation: An fMRI study of cognitive reappraisal. Group Processes \& Intergroup Relations, 11, 143-162. doi:10.1177/1368430207088035

McRae, K., Reiman, E. M., Fort, C. L., Chen, K., \& Lane, R. D. (2008b). Association between trait emotional awareness and dorsal anterior cingulate activity during emotion is arousaldependent. NeuroImage, 41, 648-655. doi:10.1016/j.neuroimage. 2008.02.030

Meyers, M. B., \& Smith, B. D. (1987). Cerebral processing of nonverbal affective stimuli: Differential effects of cognitive and affective sets on hemispheric asymmetry. Biological Psychology, 24, $67-84$.

Miller, E. K. (2000). The prefrontal cortex and cognitive control. Nature Reviews Neuroscience, 1, 59-65. doi:10.1038/35036228

Miller, E. K., \& Cohen, J. D. (2001). An integrative theory of prefrontal cortex function. Annual Review of Neuroscience, 24, 167-202. doi:10.1146/annurev.neuro.24.1.167

Moser, J. S., Hajcak, G., Bukay, E., \& Simons, R. F. (2006). Intentional modulation of emotional responding to unpleasant pictures: An ERP study. Psychophysiology, 43, 292-296. doi:10.1111/j.14698986.2006.00402.x

Moser, J. S., Krompinger, J. W., Dietz, J., \& Simons, R. F. (2009). Electrophysiological correlates of decreasing and increasing emotional responses to unpleasant pictures. Psychophysiology, 46, 17-27. doi:10.1111/j.1469-8986.2008.00721.x

Nolte, G., \& Hämäläinen, M. S. (2001). Partial signal space projection for artefact removal in MEG measurements: A theoretical analysis. Physics in Medicine and Biology, 46, 2873-2887. doi:10.1088/0031-9155/46/11/308

Ochsner, K. N., Bunge, S. A., Gross, J. J., \& Gabrieli, J. D. E. (2002). Rethinking feelings: An FMRI study of the cognitive regulation of emotion. Journal of Cognitive Neuroscience, 14, 1215-1229. doi: $10.1162 / 089892902760807212$

Ochsner, K. N., \& Gross, J. J. (2004). Thinking makes it so: A social cognitive neuroscience approach to emotion regulation. In $\mathrm{K}$. Vohs \& R. Baumeister (Eds.), The handbook of self-regulation (pp. 62-83). Mahwah: Erlbaum.
Ochsner, K. N., \& Gross, J. J. (2005). The cognitive control of emotion. Trends in Cognitive Sciences, 9, 242-249. doi:10.1016/ j.tics.2005.03.010

Ochsner, K. N., \& Gross, J. J. (2007). The neural architecture of emotion regulation. In J. J. Gross \& R. Buck (Eds.), The handbook of emotion regulation (pp. 87-109). New York: Guilford Press.

Ochsner, K. N., Knierim, K., Ludlow, D. H., Hanelin, J., Ramachandran, T., Glover, G., . . Mackey, S. C. (2004). Reflecting upon feelings: An fMRI study of neural systems supporting the attribution of emotion to self and other. Journal of Cognitive Neuroscience, 16, 1746-1772. doi:10.1162/0898929042947829

Ochsner, K. N., Ray, R. D., Cooper, J. C., Robertson, E. R., Chopra, S., Gabrieli, J. D. E., . . Gross, J. J. (2004). For better or for worse: Neural systems supporting the cognitive down- and up-regulation of negative emotion. NeuroImage, 23, 483-499. doi:10.1016/ j.neuroimage.2004.06.030

Park, C.-A., Kwon, R.-J., Kim, S., H., J., Chae, J. H., \& Kim, T. (2006, August). Decreased phase synchronization of the EEG in patients with major depressive disorder. Paper presented at the World Congress of Medical Physics and Biomedical Engineering, Seoul, Korea.

Pastor, M. C., Bradley, M. M., Low, A., Versace, F., Molto, J., \& Lang, P. J. (2008). Affective picture perception: Emotion, context, and the late positive potential. Brain Research, 1189, 145-151. doi:10.1016/j.brainres.2007.10.072

Pfurtscheller, G., \& Lopes da Silva, F. H. (1999). Event-related EEG/ MEG synchronization and desynchronization: Basic principles. Clinical Neurophysiology, 110, 1842-1857.

Phan, K. L., Fitzgerald, D. A., Nathan, P. J., Moore, G. J., Uhde, T. W., $\&$ Tancer, M. E. (2005). Neural substrates for voluntary suppression of negative affect: A functional magnetic resonance imaging study. Biological Psychiatry, 57, 210-219. doi:10.1016/ j.biopsych.2004.10.030

Phillips, L. H., Henry, J. D., Hosie, J. A., \& Milne, A. B. (2008), Effective regulation of the experience and expression of negative affect in old age. Journals of Gerontology, 63B, P138-P145.

Richards, J. M., \& Gross, J. J. (2000). Emotion regulation and memory: The cognitive costs of keeping one's cool. Journal of Personality and Social Psychology, 79, 410-424.

Rozenkrants, B., \& Polich, J. (2008). Affective ERP processing in a visual oddball task: Arousal, valence, and gender. Clinical Neurophysiology, 119, 2260-2265. doi:10.1016/j.clinph.2008.07.213

Schmidt, B., \& Hanslmayr, S. (2009). Resting frontal EEG alphaasymmetry predicts the evaluation of affective musical stimuli. Neuroscience Letters, 460, 237-240. doi:10.1016/j.neulet.2009.05.068

Schupp, H. T., Cuthbert, B. N., Bradley, M. M., Cacioppo, J. T., Ito, T., \& Lang, P. J. (2000). Affective picture processing: The late positive potential is modulated by motivational relevance. Psychophysiology, 37, 257-261.

Swick, D., Ashley, V., \& Turken, A. U. (2008). Left inferior frontal gyrus is critical for response inhibition. BMC Neuroscience, 9, 102. doi:10.1186/1471-2202-9-102

Thompson-Schill, S. L., Jonides, J., Marshuetz, C., Smith, E. E., D'Esposito, M., Kan, I. P., . . Swick, D. (2002). Effects of frontal lobe damage on interference effects in working memory. Cognitive, Affective, \& Behavioral Neuroscience, 2, 109-120. doi:10.3758/CABN.2.2.109

Thompson-Schill, S. L., Swick, D., Farah, M. J., D’Esposito, M., Kan, I. P., \& Knight, R. T. (1998). Verb generation in patients with focal frontal lesions: A neuropsychological test of neuroimaging findings. Proceedings of the National Academy of Sciences, 95, $15855-15860$.

Urry, H. L., van Reekum, C. M., Johnstone, T., Kalin, N. H., Thurow, M. E., Schaefer, H. S., . . . Davidson, R. J. (2006). Amygdala and ventromedial prefrontal cortex are inversely coupled during 
regulation of negative affect and predict the diurnal pattern of cortisol secretion among older adults. Journal of Neuroscience, 26, 4415-4425. doi:10.1523/JNEUROSCI.3215-05.2006

Viviani, R., Lo, H., Sim, E. J., Beschoner, P., Stingl, J. C., \& Horn, A. B. (2010). The neural substrate of positive bias in spontaneous emotional processing. PLoS One, 5, e15454. doi:10.1371/journal. pone. 0015454

Volkow, N. D., Fowler, J. S., Wang, G.-J., Telang, F., Logan, J., Jayne, M., . . Swanson, J. M. (2010). Cognitive control of drug craving inhibits brain reward regions in cocaine abusers. NeuroImage, 49, 2536-2543. doi:10.1016/j.neuroimage.2009.10.088
Wager, T. D., Davidson, M. L., Hughes, B. L., Lindquist, M. A., \& Ochsner, K. N. (2008). Prefrontal-subcortical pathways mediating successful emotion regulation. Neuron, 59, 1037-1050. doi:10.1016/j.neuron.2008.09.006

Wager, T. D., Keller, M. C., Lacey, S. C., \& Jonides, J. (2005). Increased sensitivity in neuroimaging analyses using robust regression. NeuroImage, 26, 99-113. doi:10.1016/j.neuroimage. 2005.01.011

Weinberg, A., \& Hajcak, G. (2010). Beyond good and evil: The timecourse of neural activity elicited by specific picture content. Emotion, 10, 767-782. doi:10.1037/a0020242 